D.O.I.: $10.3895 / \mathrm{S} 1808-04482006000300003$

\title{
GESTÃO DO CONHECIMENTO E COMPLEXIDADE - UM ESTUDO DE CASO DO SISTEMA PRODUTIVO DO SETOR DE ANÁLISES CLÍNICAS DE UM HOSPITAL UNIVERSITÁRIO
}

\section{KNOWLEDGE MANAGEMENT AND COMPLEXITY - CASE OF PRODUCTION SYSTEM OF CLINICAL ANALYSIS DEPARTMENT OF UNIVERSITY HOSPITAL}

\author{
Kamile Theis Stadnick ${ }^{1}$; Christianne Coelho de Souza Reinisch Coelho ${ }^{2}$ \\ ${ }^{1}$ Federal University of Santa Catarina - UFSC - Florianópolis - Brasil kamilets@,hotmail.com \\ ${ }^{2}$ Federal University of Santa Catarina - UFSC - Florianópolis - Brasil ccsrcoelho@terra.com.br
}

\begin{abstract}
Resumo
A concepção atual de administração e teoria organizacional destaca a criação e o uso da informação, que desempenham papel estratégico no crescimento e na capacidade de adaptação da empresa. Os administradores vêm notando que um controle preciso das atividades em suas organizações está se tornando impraticável. O fato está relacionado ao número de interações entre os indivíduos com o ambiente, interno e externo, que aumentam progressivamente. As limitações da ação gerencial clássica tornam-se evidentes quando se depara com a dificuldade ou impossibilidade de planejamento e controle totais. Desta forma, o presente artigo trata de um estudo das formas de conduta dos sistemas produtivos, sob a ótica dos sistemas adaptativos complexos. Para tanto, realizou-se um estudo de caso que teve como objetivo caracterizar o PCP (com ênfase no planejamento) do Setor de Análises Clínicas do HU/UFSC, em relação às suas linearidades e não-linearidades. Pode-se inferir que o sistema de produção em foco apresenta características de um sistema complexo adaptativo, uma vez que foram observados princípios de ação autônoma individual, até a auto-organização sistêmica. No entanto, observou-se que podem ser desenvolvidas outras características para que o sistema possa responder mais rapidamente às inquietações do ambiente.
\end{abstract}

Palavras-chave: planejamento da produção, gestão do conhecimento, complexidade.

\section{Introdução}

Segundo Choo (2003, pg. 83), “o estudo das necessidades e do uso da informação é necessariamente transdisciplinar, ligando áreas como a psicologia cognitiva, estudos de comunicação, difusão de inovações, economia, armazenamento de informações, teoria organizacional e antropologia social". 
$\mathrm{Na}$ chamada Era do Conhecimento, as organizações passaram da perspectiva de sistemas mecanicistas para sistemas orgânicos, o que faz emergir a necessidade de adequação interna das mesmas na busca de caminhos para que possam fazer frente às novas demandas sócio-econômicas. Estudiosos afirmam que o modelo newtoniano-cartesiano não atende mais às necessidades organizacionais, uma vez que o pressuposto da linearidade apresenta baixa capacidade de flexibilidade e auto-organização, restringido sua capacidade de adaptação e mudança (STACEY, 2000; MORIN, 2000 e 2001; HOCK, 2000).

Esse processo pode ser verificado na prática transpondo o exposto para a área de Administração da Produção, que teve em seu cerne, por muito tempo, as suas ações voltadas para a prescrição. As funções básicas, de planejamento, programação e controle, eram traçadas previamente e o previsto era cumprido à risca, pelo menos no âmbito teórico.

Nem tudo aquilo que é planejado e programado antecipadamente ocorre na prática, essa constatação está atrelada ao imperativo da realidade organizacional que encontra dificuldade em prever todos os possíveis cenários e fatos que poderão emergir na rotina de trabalho. Imersos em um mundo em que o número de interações entre os componentes de um sistema aumenta a cada momento, a elaboração de um PCP exige uma caracterização mais flexível, representando menor grau de rigidez.

A necessidade do reconhecimento desta realidade, com vistas à busca da coerência na gestão, levou a que se procurasse conhecer a forma como as organizações conseguem reorganizar o seu sistema de produção diante da não linearidades emergentes. $\mathrm{O}$ respaldo teórico relaciona-se à compreensão das organizações como sistemas adaptativos complexos (SAC's), os quais buscam observar e interpretar os fatos à luz da teoria da complexidade. Neste sentido, a proposta do presente artigo consiste na busca em compreender os sistemas de produção como sistemas adaptativos complexos. Para tanto, foi desenvolvido o estudo do setor produtivo de um laboratório de análises clínicas pertencente a um hospital universitário.

Assim, o artigo tem como objetivo precípuo caracterizar o PCP do setor de Análises Clínicas do Hospital Universitário Polydoro Ernani de São Thiago, pertencente à Universidade Federal de Santa Catarina (UFSC), em relação às suas linearidades e não-linearidades. Para tal fim, foram descritas as características estruturais físicas, de diretrizes e regras e de apoio informacional existentes no PCP, para então apresentar as demandas não-lineares emergentes, bem como as formas através das quais os indivíduos se organizam frente às não-linearidades, na busca de reorganizar o sistema. 


\section{Planejamento, programação e controle da produção}

A produção, como resultado de uma atividade, é oriunda de um conjunto de esforços ou de funções empregadas. O produto é o resultado. Isto remete ao conceito de sistema de produção que, conforme Harding (1981, p.12), “é um conjunto de partes inter-relacionadas, as quais quando ligadas atuam de acordo com padrões estabelecidos sobre inputs (entradas) no sentido de produzir outputs (saídas)".

O planejamento da produção compõe-se de procedimentos que preparam e organizam informações que permitem a programação e controle da produção. Conforme Erdmann (2000) o planejamento compreende a execução de três etapas básicas, a saber - projeto do produto, projeto do processo e determinação das quantidades.

No projeto do produto estão evidenciadas as características detalhadas do que será produzido. São explicitadas as quantidades de matéria-prima necessárias para a produção, o custo das mesmas, a descrição detalhada do produto, em alguns casos, o desenho, tempo limite de estocagem, entre outros.

Segundo Erdmann (2000, p.59), o projeto do processo consiste em um plano de produção que especifica as etapas e a seqüência das tarefas com intuito de obter um produto que satisfaça as especificações determinadas no projeto do produto, ao menor custo. No caso das organizações de serviços, Shostack apud Moreira (1996), sugere uma série de quatro etapas para orientar o projeto de serviços - identificação dos processos, identificação dos pontos de falha reais e potenciais, estabelecimento de tempos de execução, e análise de rentabilidade/produtividade.

Por fim, no que tange ainda ao planejamento da produção, as decisões quanto à definição das quantidades a serem produzidas envolvem aspectos da capacidade produtiva e demanda (ERDMANN, 2000).

Dando continuidade, a programação da produção consiste no estabelecimento antecipado de todas as atividades envolvidas na produção. Ela fundamenta-se em determinados princípios, que são operacionalizados através de diferentes técnicas. Concomitante a programação está o controle que acompanha a produção, tomando informações para subsidiar possíveis ações corretivas (ERDMANN, 2000). Segundo Monks (1987, p.229), “a programação segue o planejamento agregado e exprime o plano global em termos de itens específicos aos quais podem ser designadas prioridades".

Ao tratar do PCP para o âmbito da produção de serviços ressalta-se algumas especificidades. O processo produtivo de serviços exige um direcionamento mais específico por parte dos gestores, uma vez que a gestão de serviços é geralmente mais complexa do que a gestão de bens. Ainda no âmbito dos serviços, verifica-se que a intangibilidade dos mesmos incorre na dificuldade de os 
gerentes, funcionários e até mesmo dos clientes em avaliar o resultado e a qualidade do serviço prestado (GIANESI, 1996).

\section{Teoria da complexidade: contribuições para o estudo das organizações}

Os pressupostos teóricos descritos para o Planejamento e Controle da Produção podem ser extensivos ao mundo organizacional como um todo. No entanto, cabe observar que cada vez mais os estudiosos do fenômeno organizacional se dão conta de que não estão sozinhos quando percebem que suas organizações não estão funcionando bem.

Essas e outras questões que desafiam o estudo organizacional podem ser respondidas de várias formas, dependendo do enfoque com que as mesmas são olhadas. Estudiosos filiados à visão mecanicista de mundo e estudiosos da teoria da complexidade, por exemplo, respondem às indagações de modo bastante diferenciado. Conforme destaca Stacey (2000), o argumento dos teóricos da concepção mecanicista das organizações indica que a maneira dominante de pensar sobre as organizações (que teve suas origens na concepção newtoniana, na qual o universo era compreendido como um mecanismo de relógio) preconiza que o sucesso das mesmas depende da busca da estabilidade e do controle sobre meios e fins.

O todo é a simples soma das partes, e este tipo de pensamento da relação parte-todo influenciou não só os estudos das ciências em geral, mas também, foi aplicado às organizações. Esse modo de pensar fez com que gerentes conduzissem suas ações com base em predições antecipadas do futuro, escolhas deliberadas de estratégias, planejamento de longo prazo, mensuração quantitativa das atividades e o controle das mesmas, de maneira detalhada.

A perspectiva clássica, por conseguinte, pensa o fenômeno organizacional como uma estrutura bem delineada de causa e efeito linear, e a principal preocupação dos gerentes orientada por essa perspectiva é a vinculação das regras causais SE/ENTÃO. A pressuposição é de que há um conjunto de regras que são ótimas, ou seja, que produzem o mais eficiente resultado global, advinda das ações das partes ou de membros isolados da organização (STACEY, 2000).

Bauer (1999, p. 53) destaca que "a ciência, tal como historicamente conduzida, procurou sempre descobrir unicamente certezas. Todo conhecimento reduzia-se à ordem e, toda a aleatoriedade seria apenas aparência, fruto da ignorância humana”. Morin (apud BAUER, 1999, p. 53) indica que "a racionalidade constitui-se de cinco conceitos-chave: ordem, determinismo, objetividade, causalidade e, principalmente, controle”. O conhecimento das leis da natureza tinha por objetivo último controlá-la, colocá-la submissa aos desígnios do homem e, a incerteza e a desordem eram inimigas de tal projeto. "Não é à toa que toda linguagem desenvolvida pelo homem para referenciar a desordem tem conotação negativa: instabilidade, indeterminismo, incerteza, 
desordem, desequilíbrio, não-linearidade, entre outros" (BAUER, 1999, p. 53).

Uma outra perspectiva para responder às muitas indagações as quais se colocam às organizações contemporâneas é aquela apresentada pela teoria da complexidade, a qual traz uma nova alternativa para se compreender a própria sociedade porque busca unir fatos que até então eram tratados de forma fragmentada. Essa ótica vê o mundo como um processo de fluxo e mudança com os mesmos elementos, fazendo infinitas combinações.

Os métodos de investigação desse novo enfoque são divergentes do pensamento mecanicista, e por isso, num primeiro momento alimenta algumas confusões conceituais, como na forma de pensar as instabilidades e incertezas, nos elementos que se auto-organizam e, nos sistemas que rompem com o conceito de que para se conhecer um objeto precisa-se separá-lo. Mas ao mesmo tempo não elimina a possibilidade de se agregar alguns valores das "velhas" teorias porque ela se faz da soma desses elementos. E, aí reside o grande diferencial.

Erdmann (1995, p.3), evidencia que "a complexidade e a pluralidade da vida social não está em uma realidade única. Apreender a heterogeneidade e a complexidade social ultrapassa em muito o uso dos mecanismos de redução e de identidade da vida e de sua fecundidade".

A ótica da complexidade indica que as relações sociais são marcadas pela interação entre pessoas e empresas que formam uma rede de agentes que atuam em um ambiente e procuram adaptar-se através de um processo de aprendizagem (STACEY e HOLLAND apud SILVA e REBELO, 2003, p.781). Neste sentido, segundo a visão sistêmica da vida, a assertiva de Capra (2002) elucida que o surgimento espontâneo da ordem, bem como a dinâmica da acoplagem estrutural, que ocasiona as mudanças estruturais perenes que caracterizam todos os sistemas vivos, são tidos como fenômenos básicos determinantes do processo de aprendizagem. Nesse sentido, afirma CHOO (2003, pg. 83), que "a informação é fabricada por indivíduos (agentes) a partir de sua experiência passada e de acordo com as exigências de determinada situação na qual a informação deve ser usada. Um modelo de informação deve englobar a totalidade da experiência humana: os pensamentos, sentimentos, ações e o ambiente onde eles se manifestam".

A complexidade pode ser entendida como um tipo de pensamento que não separa, mas une as relações necessárias e interdependentes de todos os aspectos da vida humana, integrando todos os modos de pensar. "Opõe-se, [portanto], aos mecanismos reducionistas e simplificadores, além de considerar as influências recebidas do ambiente interno e externo, enfrentar a incerteza e a contradição, e conviver com a solidariedade entre os fenômenos existentes" (MORIN, 2000, p. 132). Consoante esse autor, a complexidade sempre existiu e se amplia continuamente, aparecendo onde o pensamento simplificador falha.

Erdmann (1995) esclarece que não se pode entender a complexidade como complicação e imposição de dificuldades, ou seja, imbricação de ações, interações, retroações, que fogem da 
possibilidade do exercício do pensar sobre as mesmas. É algo mais profundo que emergiu várias vezes na história da filosofia. Quanto mais complexo um sistema for, maior será a sua capacidade de operar com a desordem.

Para Choo (2003), os problemas mudam com o tempo, à medida que novas informações são recebidas e as pessoas alteram suas percepções. Os problemas atuam como substitutos do ambiente de uso da informação e, como contêm uma boa dose das demandas mais evidentes do ambiente de uso, definir as dimensões do problema permite inferir as necessidades de informação de maneira mais sistêmica.

Associando o conceito de sistema com complexidade, Agostinho (2003b, p.29), enfatiza que os SAC's (sistemas adaptativos complexos) são organizações em rede formadas por inúmeros agentes, os quais são elementos ativos e autônomos, cujo comportamento é determinado por um conjunto de regras e pelas informações a respeito de seu desempenho e das condições do ambiente imediato. O comportamento global do sistema emerge, então, como efeito da combinação das interações (não-lineares) entre os diversos componentes. Agostinho (2003b) indica quatro princípios: autonomia, cooperação, agregação e auto-organização como sendo capazes de explicar como a ação-autônoma individual leva à auto-organização sistêmica.

Autonomia - a autonomia é definida como "a faculdade do indivíduo orientar sua ação com base em sua própria capacidade de julgamento" (AGOSTINHO, 2003a, p.9), que leva à flexibilidade e robustez em relação às perturbações externas. A autonomia não se contrapõe a certo grau de centralização e pode levar a adaptabilidade, aumento da diversidade, aprendizagem, redução de erros, solução de conflitos.

Cooperação - "É necessário que haja cooperação mútua e coordenação para que seja possível que o conjunto de ações de vários indivíduos autônomos convirja para o benefício do sistema" (AGOSTINHO, 2003a, p.65). Simon apud Agostinho (2003a), acrescenta ainda que, além da cooperação, existe a necessidade de coordenação. Cabe salientar que um subseqüente pilar da cooperação é a reciprocidade.

Agregação - Holland apud Agostinho (2003b), afirma que, por intermédio de uma espécie de "rotulagem", um indivíduo é capaz de reconhecer com quem ele poderá obter benefícios mútuos, selecionando as interações úteis.

Auto-organização - Quando há a iminência de uma nova situação, os indivíduos realizam uma combinação de experiências testadas em momentos anteriores para modelar a situação em que se encontram (Holland apud Agostinho, 2003b). Erdmann (1995a, p.11) evidencia que a autoorganização se apresenta como resultante da capacidade de fazer face às perturbações aleatórias do ambiente, por desorganizações seguidas de reorganizações internas, absorvendo, tolerando, integrando o erro e/ou ruído aos causadores das perturbações. 


\section{Procedimentos metodológicos}

Este trabalho caracterizou o PCP em relação às linearidades e não-linearidades do setor de Análises Clínicas do HU/UFSC, com trabalho de campo de março a junho de 2004. Configurou-se como um estudo de caso com caráter exploratório-descritivo, de abordagem qualitativa. Para a coleta de dados primários fez-se observação direta e entrevistas semi-estruturadas. Os entrevistados foram os responsáveis pelos setores de hematologia, imunologia, bioquímica e hormônios; chefe do almoxarifado; chefia técnica do SACL; e atendentes da recepção e da coleta. Os dados secundários foram obtidos por pesquisa documental e bibliográfica.

As entrevistas foram analisadas com intuito de proporcionar o entendimento da sistematização dos processos produtivos, com enfoque nas suas linearidades e nas suas nãolinearidades. Igualmente, foram analisadas as formas de ação dos colaboradores/entrevistados frente às interações com o ambiente, bem como às não-linearidades do sistema. Por fim, aplicou-se a análise vertical e horizontal que atua no sentido de integrar as percepções. A análise dos dados secundários foi feita a partir da técnica de análise documental com vistas a proporcionar a compreensão do conteúdo do material escrito. Por fim, aplicou-se a técnica da triangulação de dados visando abranger a máxima amplitude na descrição, explicação e compreensão do foco em estudo. A triangulação foi feita com intuito de detectar as ações planejadas, as emergentes e a maneira como os colaboradores reagem às condições cotidianas.

Para analisar os dados levantados, buscou-se entender o tetragrama ordem/desordem/interação/organização no setor de Análises Clínicas do HU a partir das quatro etapas apresentadas por Agostinho (2003b), capazes de explicar como a ação autônoma individual leva à auto-organização sistêmica: autonomia, cooperação, agregação e auto-organização.

\section{Resultados e discussões}

O Setor de Análises Clínicas - SACL do HU/UFSC atende aos pacientes do Hospital, bem como à comunidade em geral. Conta com 66 colaboradores, entre bioquímicos, técnicos, bolsistas e estagiários. A sua missão é "proceder análises clínicas para atender às necessidades dos clientes do HU, visando auxiliar o diagnóstico médico, bem como ser instrumento de construção de conhecimento por meio de pesquisas e estágios" (PASQUALI, 2002). O produto do SACL é a “análise de material biológico". A tecnologia instalada proporciona um mix com 271 tipos de produtos, análises ou exames.

Desta forma, o momento de ordem pode ser caracterizado pela situação em que só estão sendo requisitadas análises realizadas pelo próprio SACL. Por outro lado, a desordem pode se 
estabelecer no momento em que algum paciente necessita de uma análise que não consta no mix do laboratório do HU. Frente ao evento não-linear apresentado, podem ser verificadas duas formas de conduta em busca da nova ordem do sistema - uma ocorre quando o exame é feito com uma determinada freqüência. Mediante procedimento predeterminado, o exame é encaminhado para outro laboratório, consolidando um novo caminho. Um segundo cenário é verificado quando o exame requisitado apresenta um custo mais alto e não é solicitado com tanta freqüência. Neste caso, a requisição é encaminhada para a chefia do laboratório que decide o seu destino.

Pode-se inferir, a partir do exposto, que o princípio da autonomia não se mostra representativo frente ao evento, uma vez que, muitas vezes, quem decide acerca da conduta da ordem é somente a chefia do SACL. Neste caso, verifica-se que não é delegada a autonomia a todos os indivíduos do laboratório, o que se apóia em Simon apud Agostinho (2003b, p.43) ao abordar que "certo grau de centralização é indispensável para assegurar as vantagens da organização: coordenação, expertise e responsabilidade".

A base das unidades a serem produzidas pelo SACL é a quantidade de pacientes/dia. O setor de marcação faz o agendamento de, em média, 120 pacientes ambulatoriais por dia aos quais são acrescidos os pacientes internos, de 200 a 250 por dia e os emergenciais, aproximadamente 130 pacientes/dia. Isto resulta em um número entre 43.784 e 55.250 exames/mês, uma vez que um paciente pode demandar mais de um exame.

Sob a esfera da ordem e desordem, poder-se-ia entender que a oscilação entre as quantidades produzidas caracterizasse uma desordem. A realidade vivida no SACL do HU permite afirmar que frente à conduta social que está intrínseca aos sistemas de saúde, principalmente aos de natureza pública, a produção não pára por ter alcançado as quantidades previstas no orçamento, por exemplo. Não se pode qualificar o evento como uma desordem, uma vez que a extrapolação das quantidades se configura, praticamente, como a ordem.

No âmbito do planejamento da produção, tem-se a possibilidade de inserção de um novo produto no processo produtivo. Diante dessa iminência, é analisada uma série de fatores. São observados, o número e a freqüência de pedidos do referido exame, a perecibilidade do kit de análise, o custo de produção e, por fim, se o SUS paga o exame e quanto paga. Se isto resultar no aceite do produto, o representante do setor em que vai ser realizada a análise responsabiliza-se por capacitar seu pessoal. Neste caso, verifica-se que o princípio da ordem está estabelecido até o momento em que emerge a necessidade de inserção de um novo produto. A busca de uma nova ordem do sistema se inicia a interação para estudar a viabilidade, segue com a cooperação e a agregação - criar competência de grupo. A autonomia da linha de frente é parcial, pois a palavra final é do diretor de apoio assistencial. 
Para a operacionalização do processo produtivo, o SACL é dividido em setores de produção. Cada um produz um grupo de exames afins - imunologia, hematologia, carga viral, bioquímica, hormônios, micologia, microbiologia, parasitologia e urinálise. Existem também os setores de apoio à produção - coleta, recepção, lavação, almoxarifado e chefias. Os setores ficam sob comando dos chefes de setores, que tem atribuída a função de coordenar as atividades do seu setor em específico.

Para o entendimento do processo produtivo do SACL, escolheu-se quatro exames como exemplo: Colesterol Total realizado pelo setor de Bioquímica, Hemograma feito pelo setor de Hematologia, Proteína C Reativa - PCR no setor de Imunologia e TSH produzido pelo setor de Hormônios.

O processo produtivo segue rotina semelhante até o momento do transporte do material coletado para os setores de análise. Cada setor possui sua maneira de conduta das atividades e dos colaboradores. Na estrutura interna de um mesmo setor existem inúmeras atividades que são realizadas concomitantemente. Como cada setor realiza vários exames, cada um, em particular, possui sistematizadas várias etapas de produção até a liberação do exame.

$\mathrm{Na}$ liberação dos exames e entrega dos resultados, o Bioquímico confere o resultado do exame e libera-o ao sistema. Uma vez liberado, a recepção pode acessá-lo a partir do código do paciente, e imprimi-lo para a entrega ao mesmo.

Os indivíduos tomam decisões rápidas, uma vez que está envolvido o sentimento de dor dos pacientes e o anseio pela cura. De uma maneira geral, observou-se que os indivíduos usufruem o poder de autonomia que lhes é delegado na busca da reorganização, da retomada da ordem. A busca está fortemente calcada na cooperação para a agregação abordada por Agostinho (2003b). Há cooperação no aprendizado, muitas vezes, via tentativa e erro; pelas possibilidades de recompensas mútuas; através da imitação de indivíduos bem sucedidos ou até mesmo pelo processo de seleção cego dos comportamentos mais viáveis.

Analisa-se agora algumas questões relativas à programação da produção. As quantidades diárias de produção são estabelecidas de acordo com o padrão mencionado na etapa do planejamento - quantidade de pacientes/dia, conforme mencionado anteriormente. A variação nas quantidades não é considerada uma não-linearidade. Os procedimentos frente a uma quantidade maior de produção já está internalizada nas atitudes de cada indivíduo. Estas quantidades só são conhecidas quando os materiais coletados chegam aos setores.

A aquisição de materiais tem uma configuração um pouco diferente das organizações privadas. Por pertencer a uma instituição de natureza pública, o SACL realiza processo licitatório para compra da maioria dos materiais. Evidencia-se algumas particularidades verificadas no processo de compra - alguns itens ficam fora do contrato, não são licitados devido ao seu uso 
temporário. Neste caso, quando é detectada a necessidade de material, o almoxarifado libera uma autorização de compra e, dependendo da urgência, o período de recebimento pode variar de 2 a 7 dias. Pode ocorrer também de um material acabar antes do previsto, fato que pode emergir ou pelo aumento de exames que demandam o material ou pelo cálculo errado das necessidades. Neste caso, é feito um aditivo ao contrato que dá direito a um acréscimo de até $25 \%$ no fornecimento das quantidades estabelecidas. O contrário também é possível - no caso de não utilização de um material, pode-se diminuir em até $25 \%$ o fornecimento. Neste caso, os materiais são trocados por algum item que apresente demanda maior no período. O recebimento dos materiais é parcelado.

Quanto aos trâmites de materiais, observa-se que não provocam momentos de desordem. Nessas condições os indivíduos procedem de forma automática frente a momentos de tendência à desordem do sistema. Mas verificou-se um evento de não-linearidade - o atraso da entrega de material. Ele é comunicado assim que se detecta a desordem. Neste sentido, podem ser observados os princípios de agregação, cooperação e auto-organização na medida em que os indivíduos se comunicam para o alcance da nova ordem, bem como da auto-organização.

$\mathrm{Na}$ etapa de programação também são evidenciadas as atividades de manutenção e limpeza dos equipamentos. Um momento de desordem, na etapa da programação, são os problemas com alguma máquina de análise. Neste caso, os próprios indivíduos do setor iniciam o processo de análise da máquina, listando os possíveis problemas. Eles mesmos vão tentando consertá-la. Caso consigam encontrar o problema, o mesmo é solucionado, retomando-se à ordem. Neste caso, verifica-se a presença dos princípios da administração complexa - autonomia, cooperação e agregação, apresentados por Agostinho (2003). Acrescenta-se que quando as relações são propícias, (...) os indivíduos podem vir a cooperar através de um aprendizado, via tentativa e erro, das possibilidades de recompensas mútuas, através da imitação de outros indivíduos bem sucedidos (...) (AXELROD apud AGOSTINHO, 2003b, p.63).

As atividades envolvidas na etapa da programação não apresentaram muitos eventos nãolineares. Poucos momentos de desordem foram verificados. Impera o sentimento de que a produção não pode parar. Muitos fatos que foram observados, aparentes desvios, não podem ser considerados uma desordem uma vez que acontecem freqüentemente e os indivíduos reagem muito rapidamente frente aos mesmos.

Destaca-se como um evento não-linear do SACL a requisição do exame chegar a algum setor sem estar acompanhada do material para análise. De imediato, um colaborador do setor inicia o processo de rastreamento. Este procedimento caracteriza autonomia, uma vez o próprio setor se encarrega de encontrar o material. Os demais setores procuram o material em seus locais, encontrando o material, a ordem é estabelecida, o que deve ser entendido como cooperação, 
associada à reciprocidade - que só pode ocorrer caso cada indivíduo seja capaz de reconhecer o outro de interações passadas e lembrar como este se comportou.

A troca de etiquetas nos tubos de coleta também foi verificada. Neste caso, há coleta de material de um paciente e o identifica com etiqueta de outro paciente. Normalmente o médico desconfia do resultado e comunica ao SACL o ocorrido. Sendo assim, refaz-se os exames no mesmo dia em que o paciente esteve no laboratório para a coleta. Diante de tal evento pode-se afirmar que o princípio da autonomia faz parte do processo quando os indivíduos exercem mecanismos de ação rumo ao equilíbrio do sistema. "A autonomia dos componentes de um sistema faz com que estes sejam sistemas extremamente flexíveis e robustos em relação às percepções externas" (AGOSTINHO, 2003, p.40). A percepção externa, neste caso, pode ser dita como o caso de o médico desconfiar do resultado tido e entrar em contato com o SACL que rapidamente procede em relação ao ocorrido.

Por fim, têm-se os controles de qualidade, de custos, das quantidades e da movimentação de materiais. O controle de qualidade é o mais evidente e desenvolvido; subdivide-se em controle interno e controle externo. O primeiro é realizado pelos chefes de cada setor. O controle de qualidade externo é feito por duas organizações - a Sociedade Brasileira de Patologia Clínica (SBPC) e a Sociedade Brasileira de Análises Clínicas (SBAC).

O controle da qualidade apresentou momentos de desordem. A ordem do sistema pode ser abalada a partir da detecção de um resultado não condizente. Nestes casos o responsável do setor no qual a não-linearidade foi detectada inicia o rastreamento do problema. São tomadas as medidas necessárias até que um novo teste de qualidade seja feito. Os indivíduos do setor têm autonomia para tomar os procedimentos necessários à correção do problema. Agindo em conjunto os indivíduos usufruem momentos de cooperação na busca pela agregação para que a nova ordem do sistema seja estabelecida.

\section{Considerações finais}

A concepção atual de administração e teoria organizacional destaca a criação e o uso da informação, que desempenham papel estratégico no crescimento e na capacidade de adaptação da empresa. As organizações, sob novas formas, rompem as fronteiras da inércia na busca constante de se manterem competitivas no mercado em que atuam. Apesar de os indivíduos terem valores intrínsecos muito marcantes advindos de pensadores como Descartes, que conduzem ao pensamento linear, há estudos que evidenciam que o pensamento lateral emerge nos indivíduos, configurando uma mescla entre a linearidade e a lateralidade. 
Os sistemas não se configuram mais como formas rígidas. Assim sendo, a lateralidade do pensamento também pode ser verificada no comportamento dos mesmos e nos indivíduos que o compõem. Frente à abordagem dos Sistemas Adaptativos Complexos (SAC's) e aos princípios que conduzem a auto-organização, pode-se inferir que o PCP está assumindo uma nova conduta em sua forma de gestão. Verifica-se que quanto mais complexa é a configuração do sistema organizacional, maior precisa ser sua flexibilidade para que possam ser respondidas as demandas do sistema em tempo hábil.

Tomando em conta esta realidade, a proposta do presente trabalho teve como objetivo geral conhecer a forma como se caracteriza o PCP do SACL do HU/UFSC à luz dos pressupostos teóricos dos SAC's. Para tanto, foram descritas as etapas do PCP em foco, bem como detectadas as não-linearidades emergentes no dia-a-dia. Buscou-se explicitar os mecanismos incorporados ao PCP a partir da Teoria da Complexidade por intermédio da descrição da forma como a açãoautônoma individual leva à auto-organização sistêmica. Por fim, foram apresentadas algumas considerações acerca das condições básicas para a gestão autônoma.

No tocante aos fatores que levam à gestão autônoma, evidenciou-se a existência de formas de conduta características dessa categoria de gestão nas dependências do SACL. Tal afirmação pode ser aferida através da presença de equipes auto-gerenciadas, da capacidade de julgamento e argumentação dos indivíduos e, por fim, pelo fato da comunicação ser um dos modos de influência predominante nos locais pesquisados.

Possivelmente, em virtude da esfera social intrínseca à realidade do HU, os indivíduos assumem como dever a tomada de decisões rápidas e eficientes por estarem imbuídos do sentimento de dor dos pacientes no anseio pela cura. De uma maneira geral, observou-se que os indivíduos usufruem do poder de autonomia que lhes é delegado na busca da reorganização, da retomada da ordem. A busca está fortemente calcada na cooperação para a agregação abordada por Agostinho (2003b).

Uma observação muito freqüente no decorrer da análise dos dados foi o fato de que diante das não-linearidades que envolviam questões monetárias para a busca da nova ordem do sistema, os indivíduos agiam com menos autonomia do que quando as não-linearidades envolviam desordens pertinentes a processos de produção que não demandavam capital financeiro para o estabelecimento da ordem. Contudo, independente de envolver ou não questões financeiras, os princípios de cooperação, agregação e auto-organização eram observados de forma bem intensiva.

O estudo, enfim, destacou que as organizações vivem, cotidianamente, período de ordem/ desordem/ interação/ organização, sem entrar em processo de desagregação conforme preconizava a perspectiva clássica da administração. Essa constatação dá novos rumos para o estudo da Teoria 
das Organizações e para as áreas que compõem a estrutura das organizações permitindo com que se invista mais na subjetividade e aprendizagem doa agentes que as integram e, com isso poderem se auto-organizarem continuamente.

\begin{abstract}
The present conception of administration and theory organizacional detaches the creation and the use of the information, that perform strategic paper in the growth and in the capacity of adaptation of the company. Managers have realized that an accurate activities control in their organizations has become impracticable. This fact is related with the number of interactions between individuals with internal and external organization environment, which has been increasing progressively. Limitations on classical management action get clear which the difficulty, or impossibility, of planning and total control. In this way, the present article tries a study of the forms of conduct of the productive systems, under the point of view of the systems adaptativos complex. Based on this study is possible to infer that production system of Clinical Analysis Department of HU/UFSC shows characteristic that allow concluding that it can be configured as a complex adapted system, once were observed principles that conduce to individual self-action to the systemic auto organization. Nevertheless, there are evidences to affirm that still can be developed other characteristics, which will help the system of giving quickly answer to inquietude of environment.
\end{abstract}

Key-worrds: planning production; knowledge management, complexity

\title{
7. Referências
}

AGOSTINHO, M. C. E. Administração complexa: revendo as bases científicas da administração. RAE eletrônica, São Paulo, V.2, N.1, jan-jun/2003. 18p. Disponível em: www.rae.com.br/eletrônica. Acesso em: 20/02/2004.

Complexidade e organizações: em busca da gestão autônoma. São Paulo: Atlas, 2003.

BAUER, R. Gestão da mudança: caos e complexidade nas organizações. São Paulo: Atlas, 1999.

CAPRA, F. As conexões ocultas. Trad. Marcelo Brandão Cipolla. São Paulo: Cultrix, 2002.

CHOO, Chun Wei. A Organização do Conhecimento. São Paulo: Ed. SENAC, 2003.

COELHO, C. C. S. R. Complexidade e sustentabilidade nas organizações. 2001. 205f. Tese (Doutorado em Engenharia de Produção) - Centro Tecnológico, Universidade Federal de Santa Catarina, Florianópolis.

CORRÊA, H. L., GIANESI, I. Just in time, MRP II e OPT: um enfoque estratégico. São Paulo: Atlas, 1996.

ERDMANN, A. L. A complexidade no cotidiano de um sistema organizacional de cuidados de enfermagem hospitalar. Florianópolis: UFSC, 1995. (Tese de Doutorado em Enfermagem).

ERDMANN, R. H. Administração da Produção: Planejamento, programação e com trole. Florianópolis: Papa-livro, 2000 .

HARDING, H. A. Administração da produção. São Paulo: Atlas, 1981.

HOCK, D. Nascimento da era caórdica. São Paulo: Cultrix-Amana Key, 2000.

MONKS, J. G. Administração da produção. São Paulo: McGraw-hill, 1987.

MOREIRA, D. A. Administração da produção e operações. 2.ed. São Paulo: Pioneira, 1996. 
MORIN, E. Introdução ao pensamento complexo. 3. ed. Lisboa: Instituto Piaget, 2001.

Ciência com consciência. 4. ed. Rio de Janeiro: Bertand Brasil, 2000.

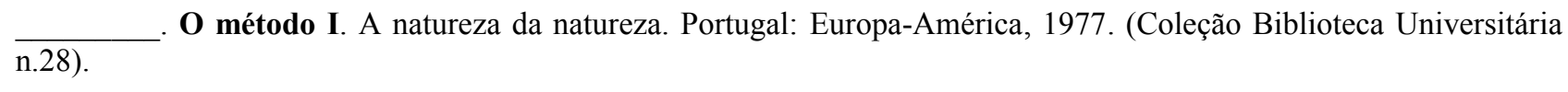

Epistemologia da complexidade. In: SCHNITMAN, D. F (Org). Novos paradigmas, cultura e subjetividade. Porto Alegre: Artes Médicas, 1996. P.274-289.

PASQUALI, R. C. Metodologia para melhoria de processos de linha de frente em serviços: aplicação em laboratório de análises clínicas. Florianópolis, 2002. (Dissertação de Mestrado em Engenharia de Produção).

SILVA, A. B.; REBELO, L. M. B. A emergência do pensamento complexo nas organizações. Revista de Administração Pública, Rio de Janeiro, V.37, N.4, Jul-Ago, 2003. 20p.

STACEY, R. D. Complexity and management. New York: Routledge, 2000.

STADNICK, K. T. A complexidade e a produção de serviços - análise do PCP do setor de análises clínicas do HU/UFSC. 2004. (105f.).Trabalho de Conclusão de Estágio (Graduação em Administração). Curso de Administração, Universidade Federal de Santa Catarina, Florianópolis, 2004.

THIOLLENT, M. Crítica metodológica, investigação social e enquete operária. 5.ed. São Paulo, Polis, 1987.

TRIVIÑOS, A. N. S. Introdução à pesquisa em ciências sociais: a pesquisa qualitativa em educação. São Paulo: Atlas, 1994.

WALDROP, M. M. Complexity: the emerging science at the edge of order and chaos. New York: Touchstone, 1992.

WHEATHLEY, M. J. A liderança e a nova ciência: apreendendo organização como um universo ordenado. São Paulo: Cultrix, 1996.

\section{Dados completos de todos os autores:}

\section{Nome completo: Kamile Theis Stadnick}

Filiação institucional: Universidade Federal de Santa Catarina

Departamento: Engenharia e Gestão Conhecimento

Função ou cargo ocupado: Mestranda

Endereço completo para correspondência (bairro, cidade, estado, país e CEP): R: João Pio Duarte

Silva - 404 - Bloco Tangará - Ap306 - Florianópolis - SC - CEP: 88.033 .000

Telefones para contato: 48991423704832345476

e-mail:kamilets@hotmail.com

\section{Nome completo: Christianne Coelho de Souza Reinisch Coelho}

Filiação institucional: Universidade Federal de Santa Catarina

Departamento: Engenharia e Gestão do Conhecimento

Função ou cargo ocupado: Professora Colaboradora

Endereço completo para correspondência (bairro, cidade, estado, país e CEP): Av. Rubens de Arruda Ramos, 1948, apto 1001, Florianópolis - SC, Brasil CEP: 88015-701 
Telefones para contato: 48 -84050503, 32226353

e-mail:ccsrcoelho@terra.com.br

Recebido para publicação em: 23/06/06

Aceito para publicação em: 06/09/06 